This item was submitted to Loughborough's Research Repository by the author.

Items in Figshare are protected by copyright, with all rights reserved, unless otherwise indicated.

\title{
A comparison of methods for the estimation of body composition in highly trained wheelchair games players
}

PLEASE CITE THE PUBLISHED VERSION

http://dx.doi.org/10.1055/s-0042-104061

PUBLISHER

(c) Georg Thieme Verlag

VERSION

AM (Accepted Manuscript)

\section{PUBLISHER STATEMENT}

This work is made available according to the conditions of the Creative Commons Attribution-NonCommercialNoDerivatives 4.0 International (CC BY-NC-ND 4.0) licence. Full details of this licence are available at: https://creativecommons.org/licenses/by-nc-nd/4.0/

\section{LICENCE}

CC BY-NC-ND 4.0

\section{REPOSITORY RECORD}

Goosey-Tolfrey, Victoria L., Mhairi Keil, Katherine S.F. Brooke-Wavell, and Sonja de Groot. 2019. "A Comparison of Methods for the Estimation of Body Composition in Highly Trained Wheelchair Games Players". figshare. https://hdl.handle.net/2134/20580. 
International Journal

of Sports Medicine

\section{A Comparison of Methods for the Estimation of Body Composition in highly-trained Wheelchair Games Players}

\begin{tabular}{|c|c|}
\hline Journal: & International Journal of Sports Medicine \\
\hline Manuscript ID & IJSM-10-2015-5275-tt.R1 \\
\hline Manuscript Type: & Training \& Testing \\
\hline Key word: & $\begin{array}{l}\text { bioelectrical impedance, air displacement plethysmography, skinfolds, } \\
\text { dual-energy X-ray absorptiometry, Paralympic sport }\end{array}$ \\
\hline Abstract: & $\begin{array}{l}\text { The purpose of this study was to assess the agreement in body } \\
\text { composition measurements of wheelchair athletes using skinfolds, bio- } \\
\text { impedance analysis (BIA) and air displacement plethysmography (ADP) } \\
\text { with the criterion method of dual-energy X-ray absorptiometry (DXA). A } \\
\text { secondary objective was to develop new skinfold prediction equations to } \\
\text { estimate \%fat for this sample. Thirty wheelchair games players were } \\
\text { recruited and the body composition outcomes of BIA, ADP, and skinfolds } \\
\text { were compared to the DXA outcomes by a paired-samples t-test } \\
\text { (systematic bias), intraclass correlation (ICC, relative agreement) and } \\
\text { Bland-Altman plots (absolute agreement). Regression models to predict the } \\
\text { \%fat as measured by DXA by the sum of skinfolds or BIA were calculated. } \\
\text { Results showed that the predictions of \%fat when using BIA, ADP or } \\
\text { skinfolds systematically underestimated the \%fat mass as measured by the } \\
\text { DXA. All ICC values, except for the measurement of fat (kg) by ADP } \\
\text { (ICC=0.702), were below 0.7. New prediction models found the } \Sigma 7 \\
\text { skinfolds and calf circumference as the best model to predict \%fat } \\
\text { (R2=0.84). In conclusion, BIA, ADP and existing skinfolds equations should } \\
\text { be used with caution when estimating \%fat of wheelchair athletes with } \\
\text { substantial body asymmetry, lower body muscular atrophy and upper body } \\
\text { muscular development. }\end{array}$ \\
\hline
\end{tabular}


1

2

3

4

5

6

7

8

9

10

11

12

13

14

15

16

17

18

19

20

21

22

23

24

25

26

27

28

29

30

31

32

33

34

35

36

37

38

39

40

41

42

43

44

45

46

47

48

49

50

51

52

53

54

55

56

57

58

59

60
A comparison of methods for the estimation of body composition in highly trained wheelchair games players 


\section{Introduction}

The assessment of body composition within both Olympic and Paralympic athletes is commonly used as a tool to help define the impact that sports training and dietary interventions have on adipose tissue. That said, when working with Paralympic athletes this becomes a challenging topic as the transferability of able-bodied athletes normative values are questionable due to the increased fat mass (FM) and decreased bone density and lean mass

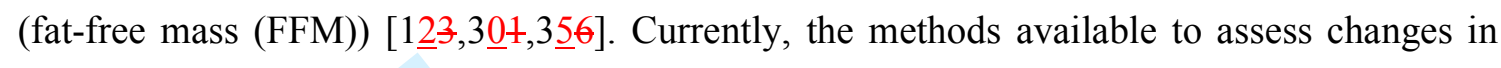
adiposity in persons who participate in wheelchair sports (e.g. individuals with a spinal cord injury (SCI), polio, amputation or with a neurological disorder) have tended to include simple and relatively cheap field-based techniques, such as skinfold callipers and bioelectrical impedance (BIA). But for obvious reasons the suitability with respect to the physical impairment of the athlete must be carefully considered. For example, hand-to-foot BIA analysers cannot be used with double leg amputees; similarly, the number and location of skinfold sites measured may need to be reduced, depending on the physical impairment type. In spite of this, these techniques have reportedly been used in persons with these aforementioned physical impairments with some degree of satisfactory results $[1,2 \underline{6} \underline{7}, 2 \underline{7} 8]$. However, previous studies are limited with small sample sizes (e.g. $n=8$ males [2주]) or with heterogeneous impairment groups (e.g. wheelchair games players comprising of both amputee and persons with a low to mid-level SCI [3틔]). Moreover, practitioners are cautious when using skinfolds since FM is typically underestimated in individuals with a SCI when using skinfolds $[2 \underline{5} 4,3 \underline{5} 6]$ and the general conclusions have stated the need for larger sample sizes so that an appropriate skinfold prediction equation can be developed.

With respect to other techniques, then to the authors' knowledge only one study has described the ability of air displacement plethysmography (ADP) to accurately assess body composition in persons with a SCI [ $[\underline{6} 6]$. Their results suggested that ADP is a valid method 
for the calculation of total body volume and density in persons with a SCI below T3. That said, there may be problems with the measurement of thoracic gas volume of persons above a lesion of T6 which would result in the use of predicted values taken from the able-bodied norms [56]. Additionally, the theoretical problem with the use of ADP, is the assumption of a fixed density of FFM, implying that proportions of minerals, water and proteins remain constant and are not affected by sex, body mass, age, or body composition. However, the mass of bone mineral and skeletal muscle may be substantially reduced in wheelchair athletes, hence invalidating this assumption. The use of two compartmental models that make assumptions about FM and FFM may therefore not be suitable for the use in individuals who have significant deviations from the norms, such as individuals with a physical impairment. As a result three or more compartmental models are the preferred methods of assessment of body composition for accuracy and reliability, whilst methods that are not dependent upon body density, such as dual-energy X-ray absorptiometry (DXA), may offer greater accuracy. Despite the noted difficulties with the positioning of an individual with a physical impairment on the DXA couch, Keil et al. [1의] recently found DXA to be a highly reproducible technique in the estimation of total and regional body composition of elite wheelchair basketball athletes.

It is clear that many comparative studies exist, that have assessed the accuracy of a given body composition technique to a reference method such as DXA, in a number of different cohorts, including healthy individuals [ $\underline{3} 4,2 \underline{0} 1,2 \underline{4} 5]$, young children $[1 \underline{0} 1, \underline{29} 30]$, and athletes [23]. In contrast, to help inform the selection of methodology of athletes with a physical impairment then there is very little published data available $[2 \underline{6} 7,3 \underline{5} 6]$. Therefore, the main purpose of this study was to assess the agreement in body composition measurements of trained wheelchair athletes using skinfolds, BIA and ADP with the reference method of DXA. This was done for the total group as well as for those participants with a SCI (e.g., tetraplegia 
vs. paraplegia) on the agreement. Furthermore, the second purpose was to develop new skinfold prediction equations to estimate percentage fat in wheelchair athletes with a SCI.

\section{Methods}

Participants: The study was approved by University Research Ethics Committee and the National Research Ethics Service and participants provided written informed consent prior to data collection. Participants included thirty male trained wheelchair games players from the sports of wheelchair basketball $(\mathrm{n}=19 ; 29 \pm 7 \mathrm{yrs}$ with a body mass of $72.1 \pm 13.1 \mathrm{~kg})$ and wheelchair rugby $(\mathrm{n}=11 ; 32 \pm 5 \mathrm{yrs}$ with a body mass of $68.2 \pm 10.7 \mathrm{~kg})$. Diagnoses were spinal cord injury from the lumbar to cervical region $(n=22)$, diastrophic dysplasia dystrophic dysphasia $(n=3)$, hip damage $(n=1)$ and lower limb damage (amputation $(n=4))$, indicative of physical disabilities that meet the eligibility criteria to participate in wheelchair basketball and wheelchair rugby. All participants were considered trained having competed at a national level on a regular basis. As body composition estimates may differ between individuals with a high and low SCI, subgroups comprising of persons with paraplegia $(n=11)$ and tetraplegia $(n=11)$ were formed. This study has been performed in accordance with the ethical standards of the International Journal of Sports Medicine [14ㄷ].

Experimental Design: Each individual attended a single session in a euhydrated state having refrained from exercise and consuming alcohol and caffeine for 12 hours, and eating or drinking at least 2 hours before each testing session to minimise variation in gastrointestinal contents and hydration status. Urine osmolality was assessed using an Osmocheck (Vitech Scientific Ltd, West Sussex, UK) to determine hydration status. Every participant underwent a whole-body DXA scan and participated in an anthropometry session. Additional measurements using the techniques of air displacement plethysmography (ADP, also known 
by the commercial term BODPOD) and bioelectrical impedance analysis (BIA) were also undertaken for those participants where standard electrode placement sites were accessible and electrode placement was possible.

Dual-energy X-ray absorptiometry (DXA): Body composition was assessed using a Lunar Prodigy Advance DXA scanner (GE Lunar, Madison, WI, USA) running version 12.20 enCORE 2006 software. Standard quality assurance and stability monitoring of the DXA scanner was performed with daily measurement of the GE-Lunar calibration block and aluminium/water bath spine phantom prior to the use of the machine to detect and correct for any drift. The same trained operator performed all scans and analyses. Short-term precision for DXA measurements were determined in a previous study [1 $\underline{8} 9]$, using the same scanner, operators and in the same cohort as participants for the present study. CV values for all whole body measurements were $<2.0 \%$, and, with the exception of arm FM $(\mathrm{kg})(\mathrm{CV}=7.8 \%)$, ranged between $0.1-3.7 \%$ for all segmental measures of bone mass, FM, and lean tissue mass (LTM). Participants wore loose fitting, light-weight clothing with no metal or reflective material, and all jewellery and prostheses were removed where possible. Participants were asked to identify any metal fixtures (e.g. surgical pins) prior to the scans being performed and such fixtures were flagged as artefact on analysis. Each individual was aligned supine on the bed and appropriately positioned as closely as possible to the standard protocols. Positions that may have produced spasms or other movement and any discomfort were minimized and enough time allowed for any spasm generated on positioning to subside before scanning. Velcro restraints were applied around participants' knees and ankles to minimise movement during the scan, unless this was not possible because of the disability. Afterwards, the participants were positioned on the DXA-bed in a supine position as close as possible to standard positioning protocol, with Velcro straps used to help keep the legs still during 
measurement. The analyses of all scans were performed by the same operator to avoid any inter-observer variability. The total body scan was used to gain the outcome measures which were: total body FM, total body fat percentage ( $\%$ fat), total LTM and bone mineral content (BMC). To allow for comparison with other methods FFM was calculated as LTM +BMC.

Anthropometry: For participants unable to assume a standing position, body height was measured from the heel to the crown of the head in the supine position to the nearest $0.1 \mathrm{~cm}$ with a Luftkin measuring tape (Cooper Tools, Apex, USA). For participants who had a double amputation, height was measured using the same methodology, but to the point of amputation. For participants who were unable to lie straight or who had chronic contractures, body height was calculated from the sum of body segments.

Skinfolds: Eight skinfold sites were obtained from all participants, unless access to specific skinfold sites was inhibited due to disability or absence of limbs, in which case, as many measurements were taken as possible. All measurements were made in accordance with the guidelines stated by International Society for Advancement of Kinanthropometry (ISAK) using Lohman et al. [2트] for site locations, by the same trained investigator, using a set of Harpenden Skinfold Callipers (Baty International, West Sussex, UK). The eight sites included the following sites: biceps, triceps, subscapular, iliac crest, supraspinale, abdominal, anterior front thigh and medial calf. For non-wheelchair bound individuals, skinfold measurements were taken in the anatomical reference position (standing up). For wheelchair-bound athletes, skinfold measurements were taken in the seated position in a standardised seat without arm rests to allow for better access to the iliac crest and supraspinale. Each measurement was taken in duplicate and an average of the two measurements was recorded. Body density was calculated using the equations from Katch and McArdle [1교, Withers et al [37], the three 
and four skinfold equations of Durnin and Womersley [910] and Sloan and Weir [3 $\underline{3} 4]$. Body fat percentage was then estimated using the Siri equation [32 3$]$ : $\%$ fat $=(4.95 /$ density -4.50$)$ $\mathrm{x} 100$.

Bioelectrical impedance: Body composition was assessed using the Multiple Frequency Bioimpedance Meter (Bodystat 1500, Isle of Man, UK). Participants were asked to remove socks and jewellery before lying down in the supine position on a non-conductive surface for ten minutes, for standardisation purposes. Two electrodes were placed on the posterior surface of the right hand, at the distal end of the third metacarpal and between the styloid processes of the radius and ulna. Where possible, two electrodes were placed on the anterior surface of the right foot, at the end of the second metatarsal and between the medial and lateral malleoli of the ankle. For single leg amputees missing their right foot, the left foot was used instead and for double leg amputees, this technique was not used. Body composition was determined by the measurements of resistance made at $50 \mathrm{kHz}$, using the previously validated prediction equations of Lukaski et al. [2223].

Air displacement plethysmography: Body composition was assessed using a commercially accessed BODPOD (BODPOD, Life Measurements, Concord, CA). Participants were asked to wear tight fitting swim wear or in the absence of such attire, small shorts were worn, all prostheses and items of jewellery were removed and participants were provided with a tight fitting nylon cap to cover their hair. A two-point calibration was conducted, using an empty chamber prior to each individual assessment. Participants who were able to stand were weighed using the BODPOD system's electronic scales. For those who could not stand, body weight was matched using free weights (to the nearest $0.25 \mathrm{~kg}$ ) and loaded onto the scales to give a reading. On instruction, each participant entered the chamber and was asked to remain 
still throughout the assessment. A single ADP procedure consisted of two measurements of body volume, unless they differed by more than $150 \mathrm{ml}$, in which case, the system required a third measurement. Body volume was determined by the volume of air displaced, when the participant is secured in the chamber. The measured body volume was adjusted for thoracic gas volume, which was estimated according to the methods described by Dempster and Aitkens [ $[78]$. The corrected body volume was used in combination with body mass and height to determine body density, from which percentage FM was estimated. All estimations were calculated using prediction equations integral to the system's software. Data pertaining to fat and muscle mass in kilograms and percentages were displayed on the system's monitor and were recorded.

\section{Statistical analysis}

The assumption of normality was checked for the body composition outcome measures by a Shapiro-Wilk test and visual inspection of the q-q plot and the box plot of the data. A OneWay ANOVA and a Tukey post-hoc test were performed on height, body mass, calf circumference and the DXA outcomes to check for differences between athletes with a tetraplegia, paraplegia and other disability. A paired samples t-test was performed to test for systematic bias between the DXA outcomes and the other body composition outcomes (BIA, ADP, skinfolds). Intra-class correlations coefficients (ICC, two-way random, absolute agreement) were computed to test the relative reliability between the DXA outcomes and the outcomes of the other body composition measurement techniques. ICC's were considered sufficient when $>0.8$, moderate when 0.7 to 0.8 , and insufficient when $<0.7$ [ $\underline{36} z$ ] . Systematic bias and relative reliability were checked for the total group as well as for the groups with a paraplegia and tetraplegia separately. Bland-Altman plots with $95 \%$ limits of agreement were 
made to determine absolute reliability, i.e. underlying trends and within-subject differences in the results [낙].

Lastly, new equations for wheelchair games players to predict percentage body fat were developed using univariate regression analyses with percentage body fat measured by DXA as dependent variable and as independent variable one of the following variables: $\%$ fat measured by BIA, sum of three or four skinfolds used by Durnin and Womersley [910] or the sum of seven skinfolds as used by Withers et al. [37]. Different regression models were tested (e.g. linear, log, quadratic) and the models with the highest explained variance were finally chosen. In a secondary analysis, age or calf circumference (chosen as a measure indicative of muscle atrophy) were added to these models to check whether it improved the explained variance of the regression model. Level of significance was set at $p<0.05$.

\section{Results}

$\underline{\text { Height }(p=0.31) \text { and body mass }(p=0.31) \text { were not significantly different between the groups }}$ with a tetraplegia, paraplegia and other disability. The calf circumference of athletes with another disability was significantly different compared to the SCI groups $(p=0.01)$. Post-hoc $\underline{\text { test results showed that athletes with another disability showed a larger calf circumference }}$ compared to athletes with a tetraplegia. All participants $(n=30)$ underwent a DXA scan, yet due to the array of physical impairments not all participants were able to be measured via all the body composition field-based methods due to the limitations described previously and problems accounted with access to the BODPOD by the athletes with tetraplegia. This resulted in 28 participants being measured via the methods of BIA, 18 via the methods of ADP and up to 27 participants were able to have all the skinfold sites taken. Importantly, all participants were noted as being euhydrated as determined via the osmolality of the waking urine sample that was analysed on arrival to the laboratory prior undertaking the BIA 
measurement. The DXA assessment showed a total body fat percentage for the total group of wheelchair games players as $25.0 \pm 6.6 \%$. No significant differences were found in DXA outcomes between athletes with a tetraplegia and paraplegia_or between tetraplegia and the group with another disability. However, athletes with paraplegia had a significantly higher \%fat and significantly lower FFM (kg) compared to the group with another disability.

Systematic bias: Table 1 shows the mean and standard deviations of all body composition outcome measures and the results of the systematic bias testing. Compared to the DXA, the BIA and ADP techniques systematically overestimated FFM while they systematically underestimated FM and percentage FM. The predictions of \% fat of all skinfold measurement formulas also systematically underestimated the percentage FM as measured by the DXA. These results were similar for the total group as well as for those with tetra- and paraplegia.

Agreement: Table 1 shows the results for relative agreement between DXA outcomes and the other body composition measurement techniques. All ICC values, except for the measurement of FFM (kg) by BIA and ADP (resp, ICC $=0.824$ and 0.877 ) and fat $(\mathrm{kg})$ by ADP (ICC $=0.702$ ), were below 0.7 , indicating that the relative agreement of FM measured by BIA, $\%$ fat measured by BIA and ADP and skinfold body composition outcomes with the reference DXA measurement was insufficient. Similar results were found for people with a tetra- and paraplegia. Figures 1A-F show the absolute agreement between $\%$ fat measured by the DXA measurement and measured by the BIA, ADP or skinfolds formulas. The Bland-Altman plots clearly show that the \% fat measured by the DXA is systematically higher for almost all participants with all body composition measuring technique. The smallest mean difference with the DXA was found for the ADP and three skinfolds formula of Durnin and Womersley 
[910] (both a mean difference of $6.1 \%$ ) but with high $95 \%$ confidence intervals of the difference: -3.4 to 15.5 and -2.2 to 14.4 , respectively.

New equations: The relationship between skinfold thicknesses and \% fat by DXA seemed curvilinear (Figure 2) and The quadratic regression equations showed the best explained variances. Table 2 shows the regression models to predict the $\%$ fat as measured by DXA by the sum of three, four or seven skinfolds or the \% fat measured by BIA in wheelchair games players. Furthermore, the effect of adding age or calf circumference to the models is shown. The best model, with the highest $\mathrm{R}^{2}$, to predict $\%$ fat is the one with the 7 skinfolds and calf circumference $\left(\mathrm{R}^{2}=0.84\right)$, see formula 1 below.

Formula 1: $\quad \%$ Body fat $=-3.04+0.41 \cdot \sum \mathrm{SF} 7-0.001 \cdot \sum \mathrm{SF} 7^{2}+0.03 \cdot$ Calf $\underline{\text { circumference }}$

The models using the sum of three skinfolds showed also a quite high explained variance $\left(\mathrm{R}^{2}=0.74-0.75\right)$, see formula 2 below, and were better compared to the models using four skinfolds $\left(\mathrm{R}^{2}=0.62-0.70\right)$ or the $\%$ fat measured by BIA as independent variable $\left(\mathrm{R}^{2}=0.46\right.$ $0.51)$

Formula 2: $\%$ Body fat $=-5.04+1.46 \cdot \sum \mathrm{SF} 3-0.001 \cdot \sum \mathrm{SF}^{2}$

\section{Discussion}

This study contributes to the search for a valid field-based body composition technique in highly trained male wheelchair games players and extends previous studies to include the methods of ADP and identifies the suitability of methods with respect to SCI lesion level. In the present study we employed DXA as the criterion method and the mean \% fat of $25 \pm 7 \%$ is similar to those values reported for other USA and Japanese male wheelchair athletes $[1 \underline{5} 6,2 \underline{5} 6,2 \underline{6} 7]$ and male athletes from other British cohorts [1ㅍz]. Furthermore, this 
data demonstrates how high training loads have a positive influence on $\%$ fat since the aforementioned value is substantially lower than the $\sim 30 \%$ body fat that has been reported in sedentary, disabled participants [1 $\underline{6} 7,2 \underline{3} 4]$. However, $\%$ fat estimates in disabled athletes may not be comparable with those in other populations. In wheelchair athletes, body FM may be typical relative to sedentary controls [3 $\underline{5} 6]$. However, muscle atrophy and the related low FFM contribute to a lower body mass, and hence an artefactually high estimate of $\%$ fat. As such $\%$ fat is probably a less appropriate measure of obesity in wheelchair athletes.

No difference in body composition was found between players with tetraplegia and paraplegia while a difference was found between players with paraplegia and other disability. This difference could result partly from muscle atrophy and hence lower FFM in the paraplegic athletes, whilst athletes with other disability (e.g. amputation) are likely to exhibit much less muscle atrophy. A comparable \% fat in those with tetraplegia and paraplegia was found before [3푸].

This study found each technique showed substantial systematic error and significantly underestimated FM (\% and $\mathrm{kg})$ and overestimated FFM $(\mathrm{kg})$ relative to DXA. The mean bias for ADP, BIA and both Durnin skinfold formulae was 5.8-6.8\%, whilst that for the other skinfold techniques was $9.9-11.6 \%$. This systematic bias was observed in both people with a high and low lesion level, confirming previous literature [2 $\underline{6} 7]$. The Bland Altman plots demonstrated a large variability at both the individual and the group level in estimating FM (\%) in all techniques when compared to DXA. The limits of agreement for all techniques (e.g. | from -2.2 to $14.4 \%$ for the Durnin \& Womersley [910] 3 skinfolds formula but with comparable limits of agreement for the other techniques) were not particularly wide compared to other studies on able-bodied participants [무]. However, substantial underestimation in FM (\% and $\mathrm{kg}$ ) in comparison to DXA demonstrated that these methods cannot be used 
interchangeably at the group level and individual values should always be interpreted with caution.

Explanations for the underestimation of \% fat reported via the skinfold technique relative to DXA may be attributable to both theoretical and technical issues. Assessment of body fat from skinfold thicknesses assumes that the skinfold thicknesses at measured sites are proportional to the total body fat content. However, subcutaneous fat levels are particularly high around the waist in persons with a SCI, which could have affected the accuracy of the measures [1년. It is not known whether the proportion of fat situated subcutaneously differs between SCI and healthy controls. Moreover, assessment of some skinfold sites may not be feasible in this group due to e.g. amputation, whilst landmarks used for locating anthropometric sites may be altered. The need to make measurements in the seated position in wheelchair athletes may have affected some skinfold thicknesses (e.g. iliac crest).

Mojahedi et al. [278] stated that BIA may be a more reliable field measure than skinfolds since it measures resistance to electrical current through the body. Our data showed that BIA consistently underestimated FM (\% and $\mathrm{kg})$ and overestimated FFM $(\mathrm{kg})$ when compared to DXA which supports previous findings [278]. These findings are not surprising, as the measurement is influenced by the geometric proportions of the body, which may be altered in wheelchair athletes. Furthermore, it has previously been reported that BIA measurements are affected by a variety of factors such as nutritional status, hydration and electrolyte balance [ $\underline{8} 9$ ], body position [31ㅡ] and disease [123]. In the present study, there was an attempt to control for training, caffeine, alcohol, food and general fluids, prior to assessments, to reduce the impact that such factors would have on the assessment of body composition. Participants were all confirmed as being in a euhydrated state, nonetheless, it is highly likely that variability in the data was predominantly due to the significant body asymmetry in amputees, and muscle wastage and altered extracellular fluid distribution in the 
lower limbs of wheelchair-bound athletes [19 $20,2 \underline{3} 4,3 \underline{5} 6]$, making this technique potentially less accurate in this cohort.

This is the first study to assess the validity of ADP, using the commercially available BODPOD in elite wheelchair athletes as to the author's knowledge only one study has compared ADP with DXA within a clinical SCI population ( $\mathrm{n}=13$ mixed gender). Mean body fat estimates were substantially and significantly lower than those by DXA, whilst $95 \%$ confidence limits were high, suggesting that this technique is not a valid measure of body composition in this athletic cohort. Ballard et al [2]3] reported ADP to be an accurate technique in the estimation of body composition in female athletes. However, densitometric techniques such as ADP assume a constant density of the FM and FFM. In wheelchair athletes, particularly those with SCI, the substantial losses of skeletal muscle and bone will affect the FFM density in particular, hence affecting estimates of $\%$ fat. However, FFM density may have been expected to be lower in those with SCI, which would result in overestimation of fat content as opposed to the underestimation seen here. It is important to note that we used the commercially available BODPOD so were unable to input directly the measured thoracic gas volume and our calculations were reliant on predicted able-bodied normative data. That said, for persons above a T6 lesion it has been suggested that there may be problems with directly measuring $\mathrm{V}_{\mathrm{TG}}$ and therefore normative values may be recommended [ $[\underline{6}]$. This does open the debate to how transferable the normative thoracic gas volume values are for persons with a SCI - there may be consistent differences that would further affect the estimate of body fat content. Further research is needed in this area.

We used DXA as the reference technique in this study, but the errors associated with DXA may also be greater in this population. The technique makes assumptions about the relative attenuation of X-ray by fat and LTM [2워]; but the skeletal muscle atrophy in wheelchair athletes may make these assumptions less reliable. Furthermore, the technique can 
only resolve two components in each pixel. In pixels containing bone, fat and LTM-s cannot be resolved and are estimated based upon the composition of surrounding pixels, weighted to account for differences in distribution of fat and lean relative to the bone. In wheelchair athletes, there may be a smaller proportion of non-bone pixels in regions affected by atrophy, producing greater error in estimating soft tissue composition. Further, this atrophy will alter the distribution of fat and lean which could also make soft tissue composition estimates less reliable. As such, it is important to remember that the differences between techniques observed in this study will arise from errors in DXA as well as those in the other methods, and the errors in DXA estimates may also be larger in this population. It would thus be particularly important to evaluate techniques against a multi-component model, which allows measurements of more of the components that may vary in this population.

This study has attempted to develop a skinfold model for trained wheelchair games players. We determined that a model containing only the three upper body skinfold sites of the biceps, triceps and subscapular is similar to that containing the additional four sites of the supraspinale, abdominal, front thigh and medial calf. The former model showed an explained variance of $\mathrm{R}^{2}=0.75$ compared to $\mathrm{R}^{2}=0.69$. Theoretically, an equation including a broader range of sites should be able to take more account of inter-individual variation in fat distribution, although this advantage may be counteracted by practical limitations at some of $\underline{\text { the lower body sites. This may explain why the } 7 \text { skinfold equation explained only a little }}$ more of the variance in \%fat. However, when adding calf circumference to the model with the seven skinfold sites, this model was the best $\left(\mathrm{R}^{2}=0.84\right)$. As a practitioner the additional benefit of the model with three skinfold sites is convenience and less intrusiveness since wheelchair athletes tend to wear training trousers rather than shorts due to muscle atrophy of the lower limbs. Further validation of these predictive models is warranted. 


\section{Conclusion}

Based on the findings in this study, the agreement between the methods employed to estimate body composition at both the group and SCI impairment level, when compared to the reference method of DXA, is comparable to the agreement found in able-bodied populations. It is clear from the data presented that BIA, ADP and skinfolds should be used with caution in the estimation of body composition of elite wheelchair athletes with substantial body asymmetry, lower body muscular atrophy and upper body muscular development. Further studies need to validate the prediction equations that were derived from this study. 


\section{References}

1. Allison GT, Singer KP, Marshall RN. The effect of body position on bioelectrical resistance in individuals with spinal cord injury. Disabil Rehabil 1995; 17: 424-429

2. Visser-Meily JM, Post MW, Riphagen II, Lindeman E. Measures used to assess burden among caregivers of stroke patients: a review. Clin Rehabil 2004; 18: 601-623

3.2. Ballard TP, Fafara L, Vukovich MD. Comparison of Bod Pod and DXA in female collegiate athletes. Med Sci Sports Exerc 2004; 36:731-735

4.3. Biaggi RR, Vollman MW, Nies MA, Brener CE, Flakoll PJ, Levenhagen DK, Sun M, Karabulut Z, Chen KY. Comparison of air-displacement plethysmography with HW and bioelectrical impedance analysis for the assessment of body composition in healthy adults. Am J Clin Nutr 1999; 69:898-903

5.4. Bland JM, Altman D. Statistical methods for assessing agreement between two methods of clinical measurement. The Lancet 1986; 327: 307-310

6.5. Clasey JL, Gater DR. A comparison of hydrostatic weighing and air displacement plethysmography in adults with spinal cord injury. Arch Phys Med Rehabil 2005; 86: 2106-2113

7.6. Clasey JL, Kanaley JA, Wideman L, Heymsfield SB, Teates CD, Gutgesell ME, Thorner MO, Hartman ML, Weltman A. Validity of methods of body composition assessment in young and older men and women. J Appl Physiol 1999; 86: 1728-1738

8.7. Dempster P, Aitkens S. A new air displacement method for the determination of human body composition. Med Sci Sport Exerc 1995; 27: 1692-1697

9.8. Deurenberg P, Westrate JA, Paymans I, Van Der Kooy K. Factors affecting bioelectrical impedance measurements in humans. Eur J Clin Nutr 1988; 42:1017-1022 
10.9. Durnin JV, Womersley J. Body fat assessed from total body density and its estimation from skinfold thickness: measurements on 481 men and women aged from 16 to 72 years. Br J Nutr 1974; 32:77-97

11.10. Elberg J, McDuffie JR, Sebring NG, Salaita C, Keil M, Robotham D, Reynolds JC, Yanovski JA. Comparison of methods to assess change in children's body composition. Am J Clin Nutr 2004; 80: 64-69

12.11. Goosey-Tolfrey VL, Crosland J. Nutritional practices of competitive British wheelchair games players. Adapt Phys Activ Q 2010; 27:47-59

13.12. Goosey-Tolfrey VL, Sutton L. Disability, chronic disease and body composition. In. Stewart, A. and Sutton, L. Body Composition in Sport, Exercise and Health. Routledge; $1^{\text {st }}$ Edition. 2012; 166-186

14.13. Gray DS, Bray GA, Bauer M, Kaplan K, Gemavel N, Wood R, Greenway F, Kirk S. Skinfold thickness measurements in obese subjects. Am J Clin Nutr 1990; 51:571-577

15.14. Harriss DJ, Atkinson G. International Journal of Sports Medicine - Ethical s Standards in $\underline{s}$ Sport and eExercise $\underline{\mathrm{s} S \text { Science }}$ rResearch: 2014 update. Int J Sports Med $201309 ; 3 \underline{40}: \underline{1025-1028701-702}$

16.15. Inukai Y, Takahashi K, Wang D, Kira S. Assessment of total and segmental body composition in spinal cord injured athletes in Okayama prefecture of Japan. Acta Med Okyama 2006; 60:99-106

17.16. Jones LM, Goulding A, Gerrard DF. DEXA: a practical and accurate tool to demonstrate total and regional bone loss, lean tissue loss and FM gain in paraplegia. Spinal Cord 1998; 36:637-640

18.17. Katch FI, McArdle WD. Prediction of body density from simple anthropometric measurements in college-age men and women. Hum Biol 1973; 45: 445-455 
19.18. Keil M, Brooke-Wavell K, Totosy de Zepetnek J, Goosey-Tolfrey VL. Measurement precision of body composition variables in elite wheelchair athletes, using dual-energy X-ray absorptiometry. Eur J Sport Sci 2014; 13:1-7

20.19. Kocina P. Body composition of spinal cord injured adults. Sports Med 1997; 23:48-68

21.20. Levine JA, Abboud L, Barry M, Reed JD, Sheedy PF, Jensen MD. Measuring leg muscle and FM in humans: comparison of CT and dual-energy X-ray absorptiometry. $\mathrm{J}$ Appl Physiol 2000; 88: 452-456

22.21. Lohman TG, Roche AF, Martorell R. Anthropometric Standardization Reference Manual: Abridged Edition. Human Kinetics Publishers: Champaign, Illinois. 1988.

23.22. Lukaski HC, Bolonchuk WW, Hall CB, Siders WA. Validation of tetrapolar bioelectric impedance method to assess human body composition. J Appl Physiol 1986; 60:1327-1332

24.23. Maggioni M, Bertoll S, Margonato V, Merati G, Veicsteinas A, Testolin G. Body composition assessment in spinal cord injury subjects. Acta Diabetol. 2003; 40 Suppl $1: \mathrm{S} 183-\underline{\mathrm{S}} 186$

25.24. Maughan RJ. An evaluation of a bioelectrical impedance analyser for the estimation of body fat content. Br J Sports Med 1993; 27:63-66

26.25. Miyahara K, Wang DH, Mori K, Takahashi K, Miyatake N, Wang BL, Takigawa T, Takaki J, Ogino K. Effect of sports activity on bone mineral density in wheelchair athletes. J Bone Miner Metab 2008; 26:101-106

27.26. Mojtahedi MC, Valentine RJ, Evans EM. Body composition assessment in athletes with spinal cord injury: comparison of field methods with dual-energy X-ray absorptiometry. Spinal Cord 2009; 47:698-704 
28.27. Ozkan A, Kayıhan G, Köklü Y, Ergun N, Koz M, Ersöz G, Dellal AJ Hum Kinet. The relationship between body composition, anaerobic performance and sprint ability of amputee soccer players $2012 ; 35: 141-146$

29.28. Pietrobelli A, Formica C, Wang Z, Heymsfield SB. Dual X-ray absorptiometry body composition model: review of physical concepts. Am J Physiol 1996; 271:E941-E951

30.29. Radley D, Gately PJ, Cooke CB, Carroll S, Oldroyd B Truscott JG. Estimates of percentage body fat in young adolescents: a comparison of dual-energy X-ray absorptiometry and air displacement plethysmography. Eur J Clin Nutr 2003; 57:14021410

31.30. Reilly T, Crosland J. Nutrition and body composition. In Wheelchair Sport: A complete guide for athletes, coaches, and teachers. Human Kinetics. USA. 2010; 75-86.

32.31. Roos, A.N., Westendorp, R.G., Frölich, M. and Meinders, A.E. Tetrapolar body impedance is influenced by body posture and plasma sodium concentration. Eur J Clin Nutr 1992;46:53-60

33.32. Siri WE. The gross composition of the body. Adv Biol Med Phys 1956; 4:239-280

34.33. Sloan AW. Estimation of body fat in young men. J Appl Physiol 1967;23: 311-315

35.34. Spungen AM, Adkins RH, Stewart CA, Wang J, Pierson RN, Waters RL, Bauman WA. Factors influencing body composition in persons with spinal cord injury: a cross sectional study. J Appl Physiol 2003; 95: 2398-2407

36.35. Sutton L, Wallace J, Goosey-Tolfrey V, Scott M, Reilly T. Body composition of female wheelchair athletes. Int J Sports Med 2009; 30:259-265

36. Visser-Meily JM, Post MW, Riphagen II, Lindeman E. Measures used to assess burden among caregivers of stroke patients: a review. Clin Rehabil 2004; 18: 601-623

36. 
1

2

3

4

5

6

7

8

9

10

11

12

13

14

15

16

17

18

19

20

21

22

23

24

25

26

27

28

29

30

31

32

33

34

35

36

37

38

39

40

41

42

43

44

45

46

47

48

49

50

51

52

53

54

55

56

57

58

59

60
37. Withers RT, Craig NP, Bourdon PC, Norton KI. Relative body fat and anthropometric prediction of body density of male athletes. Eur J Appl Physiol 1987; 56:191-200
21

Georg Thieme Verlag KG. P. O. Box 3011 20, D-70451 Stuttgart, Germany. http://www.thieme.de/fz/sportsmed/index.html 
Table 1. Descriptives, systematic bias (p-value t-test) and relative agreement (ICC) of the different body composition measurement techniques compared to DXA for the total group, group with a tetraplegia and with a paraplegia.

\begin{tabular}{|c|c|c|c|c|c|c|c|c|c|c|c|c|}
\hline & \multicolumn{4}{|c|}{ Total group } & \multicolumn{4}{|c|}{ Paraplegia (basketball) } & \multicolumn{4}{|c|}{ Tetraplegia (rugby) } \\
\hline & $\mathbf{n}$ & $\begin{array}{l}\text { Mean } \pm \\
\text { SD }\end{array}$ & p-value & ICC & $\mathbf{n}$ & Mean \pm SD & p-value & ICC & $\mathbf{n}$ & Mean \pm SD & p-value & ICC \\
\hline Height (m) & 29 & $1.74 \pm 0.14$ & & & 10 & $1.68 \pm 0.10$ & & & 11 & $1.77 \pm 0.09$ & & \\
\hline Body mass $(\mathrm{kg})$ & 30 & $70.7 \pm 12.2$ & & & 11 & $68.9 \pm 9.3$ & & & 11 & $68.2 \pm 10.7$ & & \\
\hline Calf circumference $(\mathrm{cm})$ & 27 & $30.8 \pm 5.1$ & & & 9 & $28.1 \pm 4.6$ & & & 11 & $30.3 \pm 2.6$ & & \\
\hline DXA fat-free mass (kg) & 27 & $53.7 \pm 8.9$ & - & - & 10 & $50.5 \pm 6.2$ & - & - & 11 & $52.3 \pm 8.8$ & - & - \\
\hline BIA fat-free mass $(\mathrm{kg})$ & 27 & $58.1 \pm 9.7$ & $<0.001$ & 0.824 & 10 & $54.4 \pm 7.1$ & 0.020 & 0.689 & 11 & $57.7 \pm 10.4$ & $<0.001$ & 0.827 \\
\hline ADP fat-free mass $(\mathrm{kg})$ & 17 & $57.1 \pm 9.8$ & 0.002 & 0.877 & 10 & $55.1 \pm 8.5$ & 0.003 & 0.718 & - & - & - & - \\
\hline DXA fat mass (kg) & 28 & $17.2 \pm 6.1$ & - & - & 11 & $19.1 \pm 5.4$ & - & - & 11 & $15.9 \pm 5.6$ & - & - \\
\hline BIA fat mass $(\mathrm{kg})$ & 28 & $13.3 \pm 4.4$ & $<0.001$ & 0.572 & 10 & $15.4 \pm 3.9$ & 0.011 & 0.434 & 11 & $12.0 \pm 3.6$ & 0.003 & 0.565 \\
\hline ADP fat mass (kg) & 18 & $14.0 \pm 5.6$ & $<0.001$ & 0.702 & 10 & $13.8 \pm 5.5$ & 0.001 & 0.557 & - & - & - & - \\
\hline DXA fat $(\%)$ & 30 & $25.0 \pm 6.6$ & - & - & 11 & $28.4 \pm 5.6$ & - & - & 11 & $24.3 \pm 6.9$ & - & - \\
\hline BIA fat $(\%)$ & 28 & $18.4 \pm 5.5$ & $<0.001$ & 0.410 & 10 & $21.9 \pm 5.8$ & 0.009 & 0.130 & 11 & $17.4 \pm 5.2$ & $<0.001$ & 0.482 \\
\hline ADP fat $(\%)$ & 18 & $19.2 \pm 5.9$ & $<0.001$ & 0.488 & 10 & $19.9 \pm 5.9$ & $<0.001$ & 0.385 & - & - & - & - \\
\hline \multicolumn{13}{|l|}{ Skinfolds fat (\%) } \\
\hline - Katch \& McArdle & 29 & $14.3 \pm 4.2$ & $<0.001$ & 0.278 & 10 & $15.5 \pm 4.1$ & $<0.001$ & 0.173 & 11 & $14.0 \pm 5.3$ & $<0.001$ & 0.380 \\
\hline - Sloan \& Weir & 27 & $14.0 \pm 5.7$ & $<0.001$ & 0.294 & 10 & $17.8 \pm 6.1$ & $<0.001$ & 0.336 & 11 & $11.6 \pm 4.1$ & $<0.001$ & 0.162 \\
\hline $\begin{array}{l}\text { - Durnin \& Womersley } \\
\text { (3 sites) }\end{array}$ & 30 & $18.0 \pm 4.7$ & $<0.001$ & 0.468 & 11 & $19.9 \pm 4.5$ & $<0.001$ & 0.272 & 11 & $19.2 \pm 5.4$ & 0.001 & 0.610 \\
\hline $\begin{array}{l}\text { - Durnin \& Womersley } \\
\text { (4 sites) }\end{array}$ & 30 & $19.1 \pm 4.7$ & $<0.001$ & 0.443 & 11 & $19.7 \pm 5.4$ & $<0.001$ & 0.306 & 11 & $18.9 \pm 4.5$ & 0.001 & 0.543 \\
\hline - Withers et al. & 30 & $15.1 \pm 5.3$ & $<0.001$ & 0.342 & 11 & $17.4 \pm 6.3$ & $<0.001$ & 0.275 & 11 & $13.9 \pm 4.8$ & $<0.001$ & 0.339 \\
\hline
\end{tabular}


Table 2. Newly developed regression equations for wheelchair games athletes $(n=27)$ to predict percentage body fat measured by DXA from sum of three or four skinfolds, sum of seven skinfolds or percentage fat measured by BIA.

\begin{tabular}{|c|c|c|c|c|c|c|c|c|c|c|c|c|}
\hline & \multicolumn{2}{|c|}{ Constant } & \multicolumn{2}{|c|}{ SF } & \multicolumn{2}{|c|}{$\mathbf{S F}^{2}$} & \multicolumn{2}{|c|}{ Age } & \multicolumn{2}{|c|}{ Calf circumference } & \multirow[b]{2}{*}{$\mathbf{R}^{2}$} & \multirow[b]{2}{*}{ SEF } \\
\hline & Beta (SE) & p-value & Beta (SE) & p-value & Beta (SE) & p-value & Beta (SE) & p-value & Beta (SE) & p-value & & \\
\hline SF3 & $-5.04(5.00)$ & 0.32 & $1.46(0.30)$ & $<0.001$ & $-0.01(0.004)$ & 0.003 & - & - & - & - & .752 & 3.40 \\
\hline SF3 & $-5.54(5.67)$ & 0.34 & $1.45(0.30)$ & $<0.001$ & $-0.01(0.004)$ & 0.003 & $0.02(0.11)$ & 0.84 & - & - & .752 & 3.47 \\
\hline SF3 & $-4.56(6.44)$ & 0.49 & $1.36(0.32)$ & $<0.001$ & $-0.01(0.004)$ & 0.01 & - & - & $0.04(0.14)$ & 0.80 & .741 & 3.54 \\
\hline SF4 & $4.92(7.16)$ & 0.50 & $0.52(0.27)$ & 0.07 & $-0.002(0.002)$ & 0.45 & - & - & - & - & .616 & 4.23 \\
\hline SF4 & $4.75(7.76)$ & 0.55 & $0.51(0.28)$ & 0.08 & $-0.002(0.002)$ & 0.46 & $0.009(0.144)$ & 0.95 & - & - & .616 & 4.31 \\
\hline SF4 & $0.09(7.46)$ & 0.99 & $0.90(0.30)$ & 0.006 & $-0.005(0.003)$ & 0.06 & - & - & $-0.19(0.163)$ & 0.26 & .700 & 3.81 \\
\hline SF7 & $11.67(4.69)$ & 0.02 & $0.13(0.11)$ & 0.25 & $0.00(0.001)$ & 0.58 & & - & - & - & .691 & 3.80 \\
\hline SF7 & $9.98(5.56)$ & 0.08 & $0.12(0.11)$ & 0.28 & $0.00(0.001)$ & 0.58 & $0.07(0.12)$ & 0.56 & - & - & .695 & 3.84 \\
\hline SF7 & $-3.04(5.36)$ & 0.58 & $0.41(0.10)$ & $<0.001$ & $-0.001(0.001)$ & 0.06 & - & - & $0.03(0.11)$ & 0.82 & .841 & 2.78 \\
\hline BIA & $4.58(7.50)$ & 0.55 & $1.52(0.85)$ & 0.09 & $-0.02(0.02)$ & 0.41 & - & - & - & - & .459 & 5.16 \\
\hline BIA & $2.60(7.81)$ & 0.74 & $1.23(0.91)$ & 0.19 & $-0.01(0.03)$ & 0.60 & $0.16(0.17)$ & 0.36 & & - & .478 & 5.17 \\
\hline BIA & $-8.90(9.32)$ & 0.35 & $1.24(0.87)$ & 0.17 & $-0.008(0.03)$ & 0.75 & - & - & $0.46(0.23)$ & 0.05 & .514 & 4.86 \\
\hline
\end{tabular}

SF3: Sum of skinfolds of Biceps, Triceps, Subscapular [10]

SF4: Sum of skinfolds of Biceps, Triceps, Subscapular, Iliac Crest [10]

SF7: Sum of skinfolds of Triceps, Subscapular, Biceps, Supraspinale, Abdominal, Front Thigh, Medial Calf [37] 

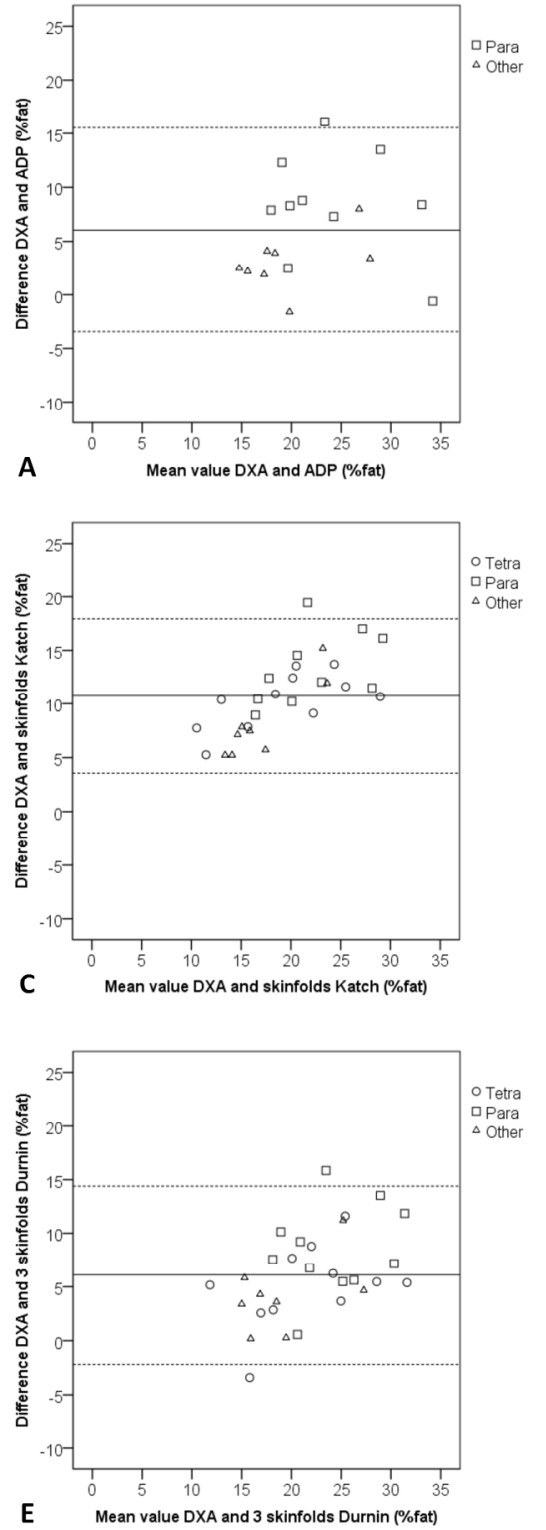
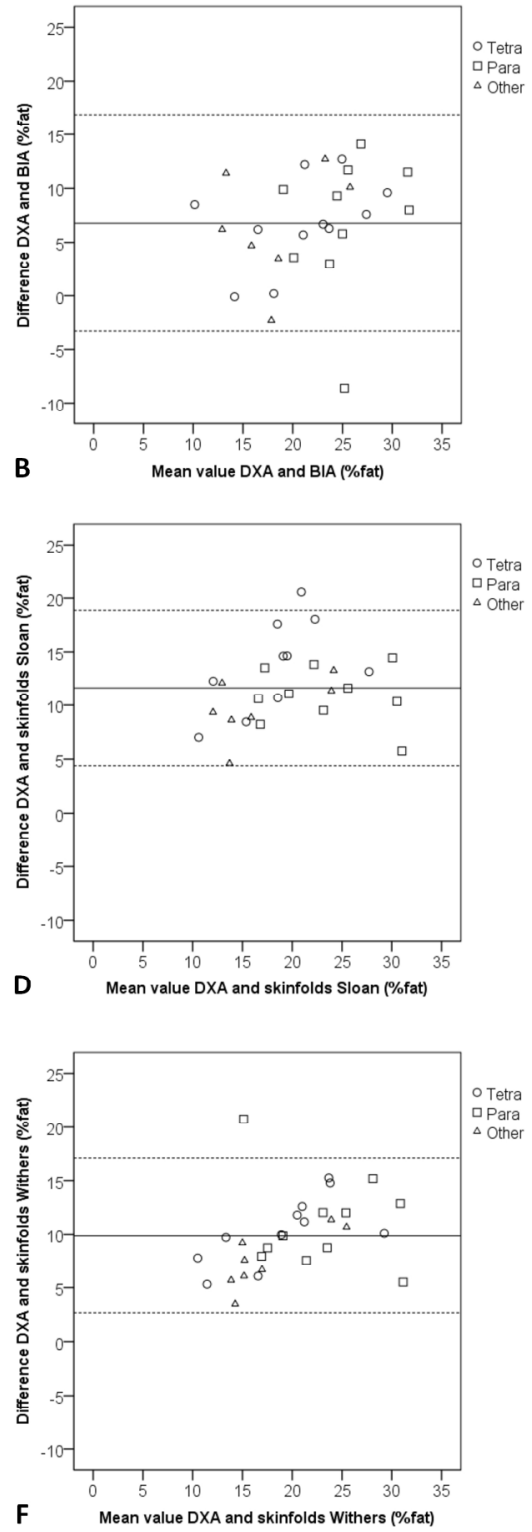

Fig. 1: Bland-Altman plots to show absolute agreement between percentage fat measured by DXA and ADP $(A)$, BIA (B), skinfold equations of Katch \& McArdle (C), Sloan and Weir (D), Durnin and Womersley (E), and Withers et al. (F). Mean values between DXA and the other technique are on the $x$-axis, and the differences between protocols are on the $y$-axis. The solid line is the mean difference across the data set for each variable. 95\% Confidence intervals are the dotted lines above and below the means. The different groups are indicated by different signs. $254 \times 338 \mathrm{~mm}(300 \times 300 \mathrm{DPI})$ 
1

2

3

4

5

6

7

8

9

10

11

12

13

14

15

16

17

18

19

20

21

22

23

24

25

26

27

28

29

30

31

32

33

34

35

36

37

38

39

40

41

42

43

44

45

46

47

48

49

50

51

52

53

54

55

56

57

58

59

60
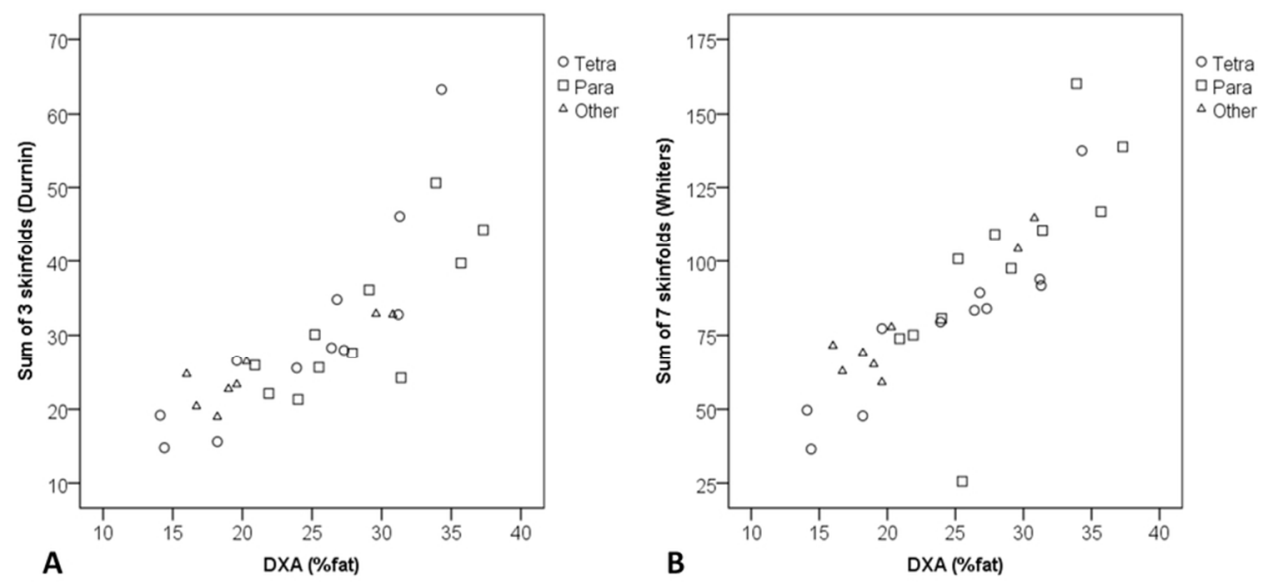

Fig. 2: Relationship between sum of $3(\mathrm{~A})$ or 7 (B) skinfolds and percentage fat measured by DXA $84 \times 37 \mathrm{~mm}(300 \times 300 \mathrm{DPI})$

Georg Thieme Verlag KG. P. O. Box 3011 20, D-70451 Stuttgart, Germany. http://www.thieme.de/fz/sportsmed/index.html 
A comparison Comparison of methods-Methods for the estimation-Estimation of body

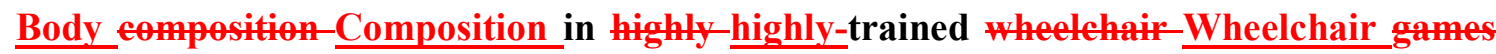
Games p Players 


\section{Introduction}

The assessment of body composition within both Olympic and Paralympic athletes is commonly used as a tool to help define the impact that sports training and dietary interventions have on adipose tissue. That said, when working with Paralympic athletes this becomes a challenging topic ${ }_{2}$ as the transferability of able-bodied athletes normative values are questionable due to the increased fat mass (FM) and decreased bone density and lean mass (fat-free mass $(\mathrm{FFM}))[1 \underline{2} 3,3 \underline{0} 1,3 \underline{5} 6]$. Currently, the methods available to assess changes in adiposity in persons who participate in wheelchair sports (e.g. individuals with a spinal cord injury (SCI), polio, amputation or with a neurological disorder) have tended to include simple and relatively cheap field-based techniques, such as skinfold callipers and bioelectrical impedance (BIA). But for obvious reasons the suitability with respect to the physical impairment of the athlete must be carefully considered. For example, hand-to-foot BIA analysers cannot be used with double leg amputees; similarly, the number and location of skinfold sites measured may need to be reduced, depending on the physical impairment type. In spite of this, these techniques have reportedly been used in persons with these aforementioned physical impairments with some degree of satisfactory results $[1,2 \underline{6} \underline{7}, 2 \underline{7} 8]$. However, previous studies are limited with small sample sizes (e.g. $n=8$ males [2 $\underline{6} 7]$ ) or with heterogeneous impairment groups (e.g. wheelchair games players comprising of both amputees and persons with a low to mid-level SCI [3틔]). Moreover, practitioners are cautious when using skinfolds since FM is typically underestimated in individuals with a SCI when using skinfolds [2프,_3 $\underline{5} 6]$ and the general conclusions have stated the need for larger sample sizes so that an appropriate skinfold prediction equation can be developed.

With respect to other techniques, then-to the authors' knowledge only one study has described the ability of air displacement plethysmography (ADP) to accurately assess body composition in persons with a SCI [ $\underline{6} 6]$. Their results suggested that ADP is a valid method 
for the calculation of total body volume and density in persons with a SCI below T3. That said, there may be problems with the measurement of thoracic gas volume of persons above a lesion of T6 which would result in the use of predicted values taken from the able-bodied norms [56]. Additionally, the theoretical problem with the use of ADP, is the assumption of a fixed density of FFM, implying that proportions of minerals, water and proteins remain constant and are not affected by sex, body mass, age, or body composition. However, the mass of bone mineral and skeletal muscle may be substantially reduced in wheelchair athletes, hence invalidating this assumption. The use of two compartmental models that make assumptions about FM and FFM may therefore not be suitable for the use in individuals who have significant deviations from the norms, such as individuals with a physical impairment. As a result three or more compartmental models are the preferred methods of assessment of body composition for accuracy and reliability, whilst methods that are not dependent upon body density, such as dual-energy X-ray absorptiometry (DXA), may offer greater accuracy. Despite the noted difficulties with the positioning of an individual with a physical impairment on the DXA couch, Keil et al. [1의] recently found DXA to be a highly reproducible technique in the estimation of total and regional body composition of elite wheelchair basketball athletes.

It is clear that many comparative studies exist, that have assessed the accuracy of a given body composition technique to a reference method such as DXA, in a number of different cohorts, including healthy individuals $[\underline{3} 4,2 \underline{0} 4,2 \underline{4}]$, young children $[1 \underline{0} 1,2930]$, and athletes [23]. In contrast, to help inform the selection of methodology of athletes with a physical impairment then there is very little published data available [2무,_3 $3 \underline{6} 6]$. Therefore, the main purpose of this study was to assess the agreement in body composition measurements of trained wheelchair athletes using skinfolds, BIA and ADP with the reference method of DXA. This was done for the total group as well as for those participants with a SCI 
(e.g., tetraplegia vs. paraplegia) on the agreement. Furthermore, the second purpose was to develop new skinfold prediction equations to estimate percentage fat in wheelchair athletes with a SCI.

\section{Methods}

Participants: The study was approved by University Research Ethics Committee and the National Research Ethics Service and participants provided written informed consent prior to data collection. Participants included thirty male trained wheelchair games players from the sports of wheelchair basketball $(\mathrm{n}=19 ; 29 \pm 7 \mathrm{yrs}$ with a body mass of $72.1 \pm 13.1 \mathrm{~kg})$ and wheelchair rugby $(\mathrm{n}=11 ; 32 \pm 5 \mathrm{yrs}$ with a body mass of $68.2 \pm 10.7 \mathrm{~kg})$. Diagnoses were spinal cord injury from the lumbar to cervical region $(n=22)$, diastrophic dysplasia dystrophic dysphasia- $(n=3)$, hip damage $(n=1)$ and lower limb damage (amputation $(n=4))$, indicative of physical disabilities that meet the eligibility criteria to participate in wheelchair basketball and wheelchair rugby. All participants were considered trained having competed at a national level on a regular basis. As body composition estimates may differ between individuals with a high and low SCI, subgroups comprising of persons with paraplegia $(n=11)$ and tetraplegia $(n=11)$ were formed. This study has been performed in accordance with the ethical standards of the International Journal of Sports Medicine [145].

Experimental Design: Each individual attended a single session in a euhydrated state having refrained from exercise and consuming alcohol and caffeine for 12 hours, and eating or drinking at least 2 hours before each testing session to minimise variation in gastrointestinal contents and hydration status. Urine osmolality was assessed using an Osmocheck (Vitech Scientific Ltd, West Sussex, UK) to determine hydration status. Every participant underwent a whole-body DXA scan and participated in an anthropometry session. Additional 
measurements using the techniques of air displacement plethysmography (ADP, also known by the commercial term BODPOD) and bioelectrical impedance analysis (BIA) were also undertaken for those participants where standard electrode placement sites were accessible and electrode placement was possible.

Dual-energy X-ray absorptiometry (DXA): Body composition was assessed using a Lunar Prodigy Advance DXA scanner (GE Lunar, Madison, WI, USA) running version 12.20 enCORE 2006 software. Standard quality assurance and stability monitoring of the DXA scanner was performed with daily measurement of the GE-Lunar calibration block and aluminium/water bath spine phantom prior to the use of the machine to detect and correct for any drift. The same trained operator performed all scans and analyses. Short-term precision for DXA measurements were determined in a previous study [1 $\underline{8} 9]$, using the same scanner, operators and in the same cohort as participants for the present study. CV values for all whole body measurements were $<2.0 \%$, and, with the exception of arm FM $(\mathrm{kg})(\mathrm{CV}=7.8 \%)$, ranged between $0.1-3.7 \%$ for all segmental measures of bone mass, FM, and lean tissue mass (LTM). Participants wore loose fitting, light-weight clothing with no metal or reflective material, and all jewellery and prostheses were removed where possible. Participants were asked to identify any metal fixtures (e.g. surgical pins) prior to the scans being performed and such fixtures were flagged as artefact on analysis. Each individual was aligned supine on the bed and appropriately positioned as closely as possible to the standard protocols. Positions that may have produced spasms or other movement and any discomfort were minimized and enough time allowed for any spasm generated on positioning to subside before scanning. Velcro restraints were applied around participants' knees and ankles to minimise movement during the scan, unless this was not possible because of the disability. Afterwards, the participants were positioned on the DXA-bed in a supine position as close as possible to 
standard positioning protocol, with Velcro straps used to help keep the legs still during measurement. The analyses of all scans were performed by the same operator to avoid any inter-observer variability. The total body scan was used to gain the outcome measures which were: total body FM, total body fat percentage ( $\%$ fat), total LTM and bone mineral content (BMC). To allow for comparison with other methods FFM was calculated as LTM +BMC.

Anthropometry: For participants unable to assume a standing position, body height was measured from the heel to the crown of the head in the supine position to the nearest $0.1 \mathrm{~cm}$ with a Luftkin measuring tape (Cooper Tools, Apex, USA). For participants who had a double amputation, height was measured using the same methodology, but to the point of amputation. For participants who were unable to lie straight or who had chronic contractures, body height was calculated from the sum of body segments.

Skinfolds: Eight skinfold sites were obtained from all participants, unless access to specific skinfold sites was inhibited due to disability or absence of limbs, in which case, as many measurements were taken as possible. All measurements were made in accordance with the guidelines stated by International Society for Advancement of Kinanthropometry (ISAK) using Lohman et al. [21] for site locations, by the same trained investigator, using a set of Harpenden Skinfold Callipers (Baty International, West Sussex, UK). The eight sites included the following sites: biceps, triceps, subscapular, iliac crest, supraspinale, abdominal, anterior front thigh and medial calf. For non-wheelchair bound individuals, skinfold measurements were taken in the anatomical reference position (standing up). For wheelchair-bound athletes, skinfold measurements were taken in the seated position in a standardised seat without arm rests to allow for better access to the iliac crest and supraspinale. Each measurement was taken in duplicate and an average of the two measurements was recorded. Body density was 
calculated using the equations from Katch and McArdle [1ㄱ], Withers et al. [37], the three and four skinfold equations of Durnin and Womersley [ㅁ10] and Sloan and Weir [3 $\underline{3} 4]$. Body fat percentage was then estimated using the Siri equation [32 3 ] $: \%$ fat $=(4.95 /$ density -4.50$)$ $\mathrm{x} 100$.

Bioelectrical impedance: Body composition was assessed using the Multiple Frequency Bioimpedance Meter (Bodystat 1500, Isle of Man, UK). Participants were asked to remove socks and jewellery before lying down in the supine position on a non-conductive surface for ten minutes, for standardisation purposes. Two electrodes were placed on the posterior surface of the right hand, at the distal end of the third metacarpal and between the styloid processes of the radius and ulna. Where possible, two electrodes were placed on the anterior surface of the right foot, at the end of the second metatarsal and between the medial and lateral malleoli of the ankle. For single leg amputees missing their right foot, the left foot was used instead and for double leg amputees, this technique was not used. Body composition was determined by the measurements of resistance made at $50 \mathrm{kHz}$, using the previously validated prediction equations of Lukaski et al.- [22 3 ] $]$.

Air displacement plethysmography: Body composition was assessed using a commercially accessed BODPOD (BODPOD, Life Measurements, Concord, CA). Participants were asked to wear tight tight-fitting swim-wear or in the absence of such attire, small shorts were worn, all prostheses and items of jewellery were removed and participants were provided with a tight fitting nylon cap to cover their hair. -A two-point calibration was conducted, using an empty chamber prior to each individual assessment. Participants who were able to stand were weighed using the BODPOD system's electronic scales. For those who could not stand, body weight was matched using free weights (to the nearest $0.25 \mathrm{~kg}$ ) and loaded onto the scales to 
give a reading. On instruction, each participant entered the chamber and was asked to remain still throughout the assessment. A single ADP procedure consisted of two measurements of body volume, unless they differed by more than $150 \mathrm{ml}$, in which case, the system required a third measurement. Body volume was determined by the volume of air displaced, when the participant is secured in the chamber. The measured body volume was adjusted for thoracic gas volume, which was estimated according to the methods described by Dempster and Aitkens [ $[8]$. The corrected body volume was used in combination with body mass and height to determine body density, from which percentage FM was estimated. All estimations were calculated using prediction equations integral to the system's software. Data pertaining to fat and muscle mass in kilograms and percentages were displayed on the system's monitor and were recorded.

\section{Statistical analysis}

The assumption of normality was checked for the body composition outcome measures by a Shapiro-Wilk test and visual inspection of the q-q plot and the box plot of the data. A OneWay ANOVA and a Tukey post-hoc test were performed on height, body mass, calf circumference and the DXA outcomes to check for differences between athletes with a tetraplegia, paraplegia and other disability. A paired samples t-test was performed to test for systematic bias between the DXA outcomes and the other body composition outcomes (BIA, ADP, skinfolds). Intra-class correlations coefficients (ICC, two-way random, absolute agreement) were computed to test the relative reliability between the DXA outcomes and the outcomes of the other body composition measurement techniques. ICC's were considered sufficient when $>0.8$, moderate when 0.7 to 0.8 , and insufficient when $<0.7$ [ $\underline{36} z$ ] . Systematic bias and relative reliability were checked for the total group as well as for the groups with a paraplegia and tetraplegia separately. Bland-Altman plots with $95 \%$ limits of agreement were 
made to determine absolute reliability, i.e. underlying trends and within-subject differences in the results $[\underline{4} 5]$.

Lastly, new equations for wheelchair games players to predict percentage body fat were developed using univariate regression analyses with percentage body fat measured by DXA as dependent variable and as independent variable one of the following variables: $\%$ fat measured by BIA, sum of three or four skinfolds used by Durnin and Womersley [910] or the sum of seven skinfolds as used by Withers et al. [37]. Different regression models were tested (e.g. linear, log, quadratic) and the models with the highest explained variance were finally chosen. In a secondary analysis, age or calf circumference (chosen as a measure indicative of muscle atrophy) were added to these models to check whether it improved the explained variance of the regression model. Level of significance was set at $p<0.05$.

\section{Results}

Height $(p=0.31)$ and body mass $(p=0.31)$ were not significantly different betweenamong the groups with a tetraplegia, paraplegia and other disability. The calf circumference of athletes

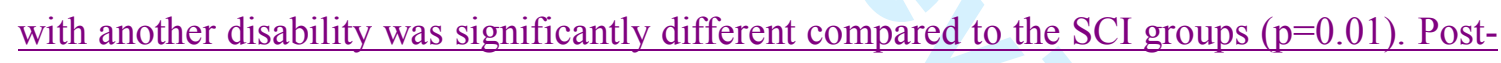
$\underline{\text { hoc test results showed that athletes with another disability showed a larger calf }}$ circumference compared to athletes with a tetraplegia. All participants $(n=30)$ underwent a DXA scan, yet due to the array of physical impairments not all participants were able to be measured via all the body composition field-based methods due to the limitations described previously and problems accounted with access to the BODPOD by the athletes with tetraplegia. This resulted in 28 participants being measured via the methods of BIA, 18 via the methods of ADP and up to 27 participants were able to have all the skinfold sites taken. Importantly, all participants were noted as being euhydrated as determined via the osmolality of the waking urine sample that was analysed on arrival to the laboratory prior undertaking 
the BIA measurement. The DXA assessment showed a total body fat percentage for the total group of wheelchair games players as $25.0 \pm 6.6 \%$. No significant differences were found in DXA outcomes between athletes with a tetraplegia and paraplegia or between tetraplegia and

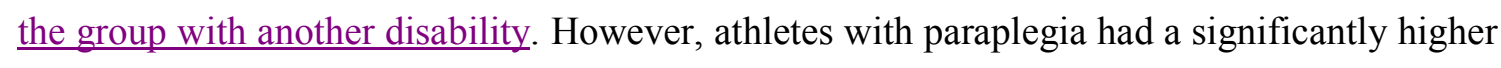
\% fat and significantly lower FFM (kg) compared to the group with another disability.

Systematic bias: Table 1 shows the mean and standard deviations of all body composition outcome measures and the results of the systematic bias testing. Compared to the DXA, the BIA and ADP techniques systematically overestimated FFM while they systematically underestimated FM and percentage FM. The predictions of \% fat of all skinfold measurement formulas also systematically underestimated the percentage FM as measured by the DXA. These results were similar for the total group as well as for those with tetra- and paraplegia.

Agreement: Table 1 shows the results for relative agreement between DXA outcomes and the other body composition measurement techniques. All ICC values, except for the measurement of FFM (kg) by BIA and ADP (resp, $\mathrm{ICC}=0.824$ and 0.877 respectively) and fat (kg) by ADP (ICC $=0.702$ ), were below 0.7 , indicating that the relative agreement of FM measured by BIA, $\%$ fat measured by BIA and ADP and skinfold body composition outcomes with the reference DXA measurement was insufficient. Similar results were found for people with a-tetra- and paraplegia. Figures 1A-F show the absolute agreement between $\%$ fat measured by the DXA measurement and measured by the BIA, ADP or skinfolds formulas. The Bland-Altman plots clearly show that the \% fat measured by the DXA is systematically higher for almost all participants with all body composition measuring technique. The smallest mean difference with the DXA was found for the ADP and three skinfolds formula of Durnin and Womersley 
[910] (both a mean difference of $6.1 \%$ ) but with high $95 \%$ confidence intervals of the difference: -3.4 to 15.5 and -2.2 to 14.4 , respectively.

New equations: The relationship between skinfold thicknesses and $\%$ fat by DXA seemed curvilinear (Figure 2), and The quadratic regression equations showed the best explained variances. Table 2 shows the regression models to predict the \% fat as measured by DXA by the sum of three, four or seven skinfolds or the $\%$ fat measured by BIA in wheelchair games players. Furthermore, the effect of adding age or calf circumference to the models is shown. The best model, with the highest $\mathrm{R}^{2}$, to predict $\%$ fat is the one with the 7 skinfolds and calf circumference $\left(\mathrm{R}^{2}=0.84\right)$, see formula 1 below.

Formula 1: $\%$ Body fat $=-3.04+0.41 \cdot-\sum \mathrm{SF} 7-0.001 \cdot-\sum \mathrm{SF} 7^{2}+0.03 \cdot-$ Calf $\underline{\text { circumference }}$

The models using the sum of three skinfolds showed also a quite high explained variance $\left(\mathrm{R}^{2}=0.74-0.75\right)$, see formula 2 below, and were better compared to the models using four skinfolds $\left(\mathrm{R}^{2}=0.62-0.70\right)$ or the $\%$ fat measured by BIA as independent variable $\left(\mathrm{R}^{2}=0.46\right.$ $0.51)$

Formula 2: $\quad \%$ Body fat $=-5.04+1.46 \cdot \sum \mathrm{SF} 3-0.001 \cdot \sum \mathrm{SF} 3^{2}$

\section{Discussion}

This study contributes to the search for a valid field-based body composition technique in highly highly-trained male wheelchair games players and extends previous studies to include the methods of ADP and identifies the suitability of methods with respect to SCI lesion level. In the present study we employed DXA as the criterion method and the mean $\%$ fat of $25 \pm 7 \%$ is similar to those values reported for other USA and Japanese male wheelchair athletes $[1 \underline{5} \theta, 2 \underline{5} 6,2 \underline{6} 7]$ and male athletes from other British cohorts [1 $\underline{1} z]$. 
Furthermore, this data demonstrates how high training loads have a positive influence on $\%$ fat since the aforementioned value is substantially lower than the $\sim 30 \%$ body fat that has been reported in sedentary, disabled participants [1무,_2 $\underline{3} 4]$. However, $\%$ fat estimates in disabled athletes may not be comparable with those in other populations. In wheelchair athletes, body FM may be typical relative to sedentary controls [3 $\underline{5} 6]$. However, muscle atrophy and the related low FFM contribute to a lower body mass, and hence an artefactually high estimate of $\%$ fat. As such $\%$ fat is probably a less appropriate measure of obesity in wheelchair athletes.

No difference in body composition was found between players with tetraplegia and paraplegia while a difference was found between players with paraplegia and other disability. This difference could result partly from muscle atrophy and hence lower FFM in the paraplegic athletes, whilst athletes with other disability (e.g. amputation) are likely to exhibit much less muscle atrophy. A comparable $\%$ fat in those with tetraplegia and paraplegia was found before previously [345].

This study found each technique showed substantial systematic error and significantly underestimated FM (\% and $\mathrm{kg})$ and overestimated FFM $(\mathrm{kg})$ relative to DXA. The mean bias for ADP, BIA and both Durnin skinfold formulae was 5.8-6.8\%, whilst that for the other skinfold techniques was 9.9-11.6\%. This systematic bias was observed in both people with a high and low lesion level, confirming previous literature [267]. The Bland Altman plots demonstrated a large variability at both the individual and the group level in estimating FM $(\%)$ in all techniques when compared to DXA. The limits of agreement for all techniques (e.g. | from -2.2 to $14.4 \%$ for the Durnin \& Womersley [910] 3 skinfolds formula but with comparable limits of agreement for the other techniques) were not particularly wide compared to other studies on able-bodied participants [ㅁ7]. However, substantial underestimation in FM (\% and $\mathrm{kg}$ ) in comparison to DXA demonstrated that these methods cannot be used 
interchangeably at the group level ${ }_{2}$ and individual values should always be interpreted with caution.

Explanations for the underestimation of $\%$ fat reported via the skinfold technique relative to DXA may be attributable to both theoretical and technical issues. Assessment of body fat from skinfold thicknesses assumes that the skinfold thicknesses at measured sites are proportional to the total body fat content. However, subcutaneous fat levels are particularly high around the waist in persons with a SCI, which could have affected the accuracy of the measures [1년. It is not known whether the proportion of fat situated subcutaneously differs between SCI and healthy controls. Moreover, assessment of some skinfold sites may not be feasible in this group due to e.g. amputation, whilst landmarks used for locating anthropometric sites may be altered. The need to make measurements in the seated position in wheelchair athletes may have affected some skinfold thicknesses (e.g. iliac crest).

Mojahedi et al. [278] stated that BIA may be a more reliable field measure than skinfolds since it measures resistance to electrical current through the body. Our data showed that BIA consistently underestimated FM (\% and $\mathrm{kg})$ and overestimated FFM $(\mathrm{kg})$ when compared to DXA which supports previous findings [278]. These findings are not surprising, as the measurement is influenced by the geometric proportions of the body, which may be altered in wheelchair athletes. Furthermore, it has previously been reported that BIA measurements are affected by a variety of factors such as nutritional status, hydration and

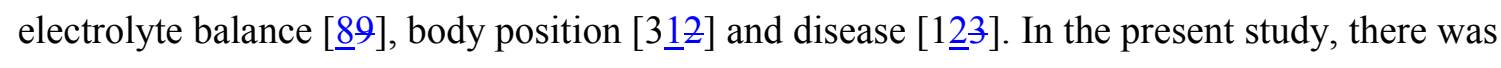
an attempt to control for training, caffeine, alcohol, food and general fluids, prior to assessments, to reduce the impact that such factors would have on the assessment of body composition. Participants were all confirmed as being in a euhydrated state, nonetheless, it is highly likely that variability in the data was predominantly due to the significant body asymmetry in amputees, and muscle wastage and altered extracellular fluid distribution in the 
lower limbs of wheelchair-bound athletes [1920,_234,3 366$]$, making this technique potentially less accurate in this cohort.

This is the first study to assess the validity of ADP, using the commercially available BODPOD in elite wheelchair athletes, as to the author's knowledge only one study has compared ADP with DXA within a clinical SCI population ( $\mathrm{n}=13$ mixed gender). Mean body fat estimates were substantially and significantly lower than those by DXA, whilst 95\% confidence limits were high, suggesting that this technique is not a valid measure of body composition in this athletic cohort. Ballard et al. [23] reported ADP to be an accurate technique in the estimation of body composition in female athletes. However, densitometric techniques such as ADP assume a constant density of the FM and FFM. In wheelchair athletes, particularly those with SCI, the substantial losses of skeletal muscle and bone will affect the FFM density in particular, hence affecting estimates of \% fat. However, FFM density may have been expected to be lower in those with SCI, which would result in overestimation of fat content as opposed to the underestimation seen here. It is important to note that we used the commercially available BODPOD so were unable to input directly the measured thoracic gas volume and our calculations were reliant on predicted able-bodied normative data. That said, for persons above a T6 lesion it has been suggested that there may be problems with directly measuring $\mathrm{V}_{\mathrm{TG}}$ and therefore normative values may be recommended [56]. This does open the debate to how transferable the normative thoracic gas volume values are for persons with a SCI - there may be consistent differences that would further affect the estimate of body fat content. Further research is needed in this area.

We used DXA as the reference technique in this study, but the errors associated with DXA may also be greater in this population. The technique makes assumptions about the relative attenuation of X-ray by fat and LTM [2워]; but the skeletal muscle atrophy in wheelchair athletes may make these assumptions less reliable. Furthermore, the technique can 
only resolve two components in each pixel. In pixels containing bone, fat and LTM-s cannot be resolved and are estimated based upon the composition of surrounding pixels, weighted to account for differences in distribution of fat and lean relative to the bone. In wheelchair athletes, there may be a smaller proportion of non-bone pixels in regions affected by atrophy, producing greater error in estimating soft tissue composition. Further, this atrophy will alter the distribution of fat and lean which could also make soft tissue composition estimates less reliable. As such, it is important to remember that the differences between techniques observed in this study will arise from errors in DXA as well as those in the other methods, and the errors in DXA estimates may also be larger in this population. It would thus be particularly important to evaluate techniques against a multi-component model, which allows measurements of more of the components that may vary in this population.

This study has attempted to develop a skinfold model for trained wheelchair games players. We determined that a model containing only the three upper body skinfold sites of the biceps, triceps and subscapular is similar to that containing the additional four sites of the supraspinale, abdominal, front thigh and medial calf. The former model showed an explained variance of $\mathrm{R}^{2}=0.75$ compared to $\mathrm{R}^{2}=0.69$. Theoretically, an equation including a broader range of sites should be able to take more account of inter-individual variation in fat distribution, although this advantage may be counteracted by practical limitations at some of the lower body sites. This may explain why the 7 skinfold equation explained only a little more of the variance in \%fat. However, when adding calf circumference to the model with the seven skinfold sites, this model was the best $\left(\mathrm{R}^{2}=0.84\right)$. As a practitioner the additional benefit of the model with three skinfold sites is convenience and less intrusiveness since wheelchair athletes tend to wear training trousers rather than shorts due to muscle atrophy of the lower limbs. Further validation of these predictive models is warranted. 


\section{Conclusion}

Based on the findings in this study, the agreement between the methods employed to estimate body composition at both the group and SCI impairment level, when compared to the reference method of DXA, is comparable to the agreement found in able-bodied populations. It is clear from the data presented that BIA, ADP and skinfolds should be used with caution in the estimation of body composition of elite wheelchair athletes with substantial body asymmetry, lower body muscular atrophy and upper body muscular development. Further studies need to validate the prediction equations that were derived from this study. 


\section{References}

1. Allison GT, Singer KP, Marshall RN. The effect of body position on bioelectrical resistance in individuals with spinal cord injury. Disabil Rehabil 1995; 17: 424-429

Z. Visser-Meily JM, Post MW, Riphagen II, Lindeman E. Measures used to assess burden
among caregivers of stroke patients: a review. Clin Rehabil 2004; 18: 601-623
3.2. Ballard TP, Fafara L, Vukovich MD. Comparison of Bod Pod and DXA in female collegiate athletes. Med Sci Sports Exerc 2004; 36:731-735

4.3. Biaggi RR, Vollman MW, Nies MA, Brener CE, Flakoll PJ, Levenhagen DK, Sun M, Karabulut Z, Chen KY. Comparison of air-displacement plethysmography with HW and bioelectrical impedance analysis for the assessment of body composition in healthy adults. Am J Clin Nutr 1999; 69:898-903

5.4. Bland JM, Altman D. Statistical methods for assessing agreement between two methods of clinical measurement. The Lancet 1986; 327: 307-310

6.5. Clasey JL, Gater DR. A comparison of hydrostatic weighing and air displacement plethysmography in adults with spinal cord injury. Arch Phys Med Rehabil 2005; 86: $2106-2113$

7.․ Clasey JL, Kanaley JA, Wideman L, Heymsfield SB, Teates CD, Gutgesell ME, Thorner MO, Hartman ML, Weltman A. Validity of methods of body composition assessment in young and older men and women. J Appl Physiol 1999; 86: 1728-1738

8.7. Dempster P, Aitkens S. A new air displacement method for the determination of human body composition. Med Sci Sport Exerc 1995; 27: 1692-1697

9.8. Deurenberg P, Westrate JA, Paymans I, Van Der Kooy K. Factors affecting bioelectrical impedance measurements in humans. Eur J Clin Nutr 1988; 42:1017-1022 
10.9. Durnin JV, Womersley J. Body fat assessed from total body density and its estimation from skinfold thickness: measurements on 481 men and women aged from 16 to 72 years. Br J Nutr 1974; 32:77-97

11.10. Elberg J, McDuffie JR, Sebring NG, Salaita C, Keil M, Robotham D, Reynolds JC, Yanovski JA. Comparison of methods to assess change in children's body composition. Am J Clin Nutr 2004; 80: 64-69

12.11. Goosey-Tolfrey VL, Crosland J. Nutritional practices of competitive British wheelchair games players. Adapt Phys Activ Q 2010; 27:47-59

13.12. Goosey-Tolfrey VL, Sutton L. Disability, chronic disease and body composition. In. Stewart, A. and Sutton, L. Body Composition in Sport, Exercise and Health. Routledge; $1^{\text {st }}$ Edition. 2012; 166-186

14.13. Gray DS, Bray GA, Bauer M, Kaplan K, Gemavel N, Wood R, Greenway F, Kirk S. Skinfold thickness measurements in obese subjects. Am J Clin Nutr 1990; 51:571-577

15.14. Harriss DJ, Atkinson G. International Journal of Sports Medicine - Ethical $\underline{s} S t a n d a r d s$ in $\underline{\text { s} S p o r t ~ a n d ~} \underline{\text { eExercise }} \underline{\mathrm{s} S c i e n c e}$ rResearch: 2014 update. Int J Sports Med $201309 ; 3 \underline{40}: \underline{1025-1028701-702}$

16.15. Inukai Y, Takahashi K, Wang D, Kira S. Assessment of total and segmental body composition in spinal cord injured athletes in Okayama prefecture of Japan. Acta Med Okyama 2006; 60:99-106

17.16. Jones LM, Goulding A, Gerrard DF. DEXA: a practical and accurate tool to demonstrate total and regional bone loss, lean tissue loss and FM gain in paraplegia. Spinal Cord 1998; 36:637-640

18.17. Katch FI, McArdle WD. Prediction of body density from simple anthropometric measurements in college-age men and women. Hum Biol 1973; 45: 445-455 
19.18. Keil M, Brooke-Wavell K, Totosy de Zepetnek J, Goosey-Tolfrey VL. Measurement precision of body composition variables in elite wheelchair athletes, using dual-energy x-ray absorptiometry. Eur J Sport Sci 2014; 13:1-7

20.19. Kocina P. Body composition of spinal cord injured adults. Sports Med 1997; 23:48-68

21.20. Levine JA, Abboud L, Barry M, Reed JD, Sheedy PF, Jensen MD. Measuring leg muscle and FM in humans: comparison of CT and dual-energy X-ray absorptiometry. J Appl Physiol 2000; 88: 452-456

22.21. Lohman TG, Roche AF, Martorell R. Anthropometric Standardization Reference Manual: Abridged Edition. Human Kinetics Publishers: Champaign, Illinois. 1988.

23.22. Lukaski HC, Bolonchuk WW, Hall CB, Siders WA. Validation of tetrapolar bioelectric impedance method to assess human body composition. J Appl Physiol 1986; $60: 1327-1332$

24.23. Maggioni M, Bertoll S, Margonato V, Merati G, Veicsteinas A, Testolin G. Body composition assessment in spinal cord injury subjects. Acta Diabetol. 2003; 40 Suppl 1:S183-ㅁ186

25.24. Maughan RJ. An evaluation of a bioelectrical impedance analyser for the estimation of body fat content. Br J Sports Med 1993; 27:63-66

26.25. Miyahara K, Wang DH, Mori K, Takahashi K, Miyatake N, Wang BL, Takigawa T, Takaki J, Ogino K. Effect of sports activity on bone mineral density in wheelchair athletes. J Bone Miner Metab 2008; 26:101-106

27.26. Mojtahedi MC, Valentine RJ, Evans EM. Body composition assessment in athletes with spinal cord injury: comparison of field methods with dual-energy X-ray absorptiometry. Spinal Cord 2009; 47:698-704 
28.27. Ozkan A, Kayıhan G, Köklü Y, Ergun N, Koz M, Ersöz G, Dellal AJ Hum Kinet. The relationship between body composition, anaerobic performance and sprint ability of amputee soccer players 2012; 35:141-146

29.28. Pietrobelli A, Formica C, Wang Z, Heymsfield SB. Dual X-ray absorptiometry body composition model: review of physical concepts. Am J Physiol 1996; 271:E941-E951

30.29. Radley D, Gately PJ, Cooke CB, Carroll S, Oldroyd B Truscott JG. Estimates of percentage body fat in young adolescents: a comparison of dual-energy X-ray absorptiometry and air displacement plethysmography. Eur J Clin Nutr 2003; 57:14021410

31.30. Reilly T, Crosland J. Nutrition and body composition. In Wheelchair Sport: A complete guide for athletes, coaches, and teachers. Human Kinetics. USA. 2010; 75-86.

32.31. Roos, A.N., Westendorp, R.G., Frölich, M. and Meinders, A.E. Tetrapolar body impedance is influenced by body posture and plasma sodium concentration. Eur J Clin Nutr 1992;46:53-60

33.32. Siri WE. The gross composition of the body. Adv Biol Med Phys 1956; 4:239-280

34.33. Sloan AW. Estimation of body fat in young men. J Appl Physiol 1967;23: 311-315

35.34. Spungen AM, Adkins RH, Stewart CA, Wang J, Pierson RN, Waters RL, Bauman WA. Factors influencing body composition in persons with spinal cord injury: a cross sectional study. J Appl Physiol 2003; 95: 2398-2407

36.35. Sutton L, Wallace J, Goosey-Tolfrey V, Scott M, Reilly T. Body composition of female wheelchair athletes. Int J Sports Med 2009; 30:259-265

36. Visser-Meily JM, Post MW, Riphagen II, Lindeman E. Measures used to assess burden among caregivers of stroke patients: a review. Clin Rehabil 2004; 18: 601-623

36. 
37. Withers RT, Craig NP, Bourdon PC, Norton KI. Relative body fat and anthropometric prediction of body density of male athletes. Eur J Appl Physiol 1987; 56:191-200

1

2

3

4

5

6

8

9

10

11

12

13

14

15

16

17

18

19

20

21

22

23

24

25

26

27

28

29

30

31

32

33

34

35

36

37

38

39

40

41

42

43

44

45

46

47

48

49

50

51

52

53

54

55

56

57

58

59

60
21

Georg Thieme Verlag KG. P. O. Box 3011 20, D-70451 Stuttgart, Germany. http://www.thieme.de/fz/sportsmed/index.html 